\title{
Heterogeneous nucleation and growth of polycrystalline silicon
}

\author{
R DHANASEKARAN and P RAMASAMY* \\ Crystal Growth Centre, A. C. College of Technology, Anna University, Madras 600025, India
}

MS received 20 March 1985; revised 5 July 1985

\begin{abstract}
The heterogeneous nucleation theory of silicon on $\mathrm{SiO}_{2}$ and $\mathrm{Si}_{3} \mathrm{~N}_{4}$ substrates has been developed using classical theory. It is shown that the experimental observations can be explained on the basis of the bond energies of $\mathrm{O}-\mathrm{H}, \mathrm{N}-\mathrm{H}$ and $\mathrm{Si}-\mathrm{H}$. A reaction model is proposed for the growth of silicon on silicon from silane, using hydrogen as a carrier gas in the temperature region $600-900^{\circ} \mathrm{C}$. The growth rate of silicon is shown to be equal to $P_{\mathrm{SiH}_{4}} / \boldsymbol{P}_{\mathrm{H}_{2}}$ when the partial pressure of hydrogen is high, and is independent of the total pressure and the partial pressure of hydrogen in the lower region.
\end{abstract}

Keywords. Silicon layer; heterogeneous nucleation; $\mathrm{SiO}_{2}$ and $\mathrm{Si}_{3} \mathrm{~N}_{4}$ substrates; growth rates; step-kink.

\section{Introduction}

Polycrystalline silicon layers are extensively used in the electronics industry. Gas phase reactions in silicon epitaxial growth have been studied widely by a number of authors and reaction models deduced from an equilibrium view point (Sladek 1971; Bloem 1970; Bylander 1962). However, the actual reaction is not in equilibrium, but rather quasi-equilibrium (Aoyama et al 1981). In the first part of this paper we present the heterogeneous nucleation phenomena of silicon on $\mathrm{SiO}_{2}$ and $\mathrm{Si}_{3} \mathrm{~N}_{4}$ substrates as a function of temperature using the classical nucleation theory (Sigsbee 1969; Dhanasekaran and Ramasamy 1982). In the second part we propose a model for the growth of silicon layers on silicon from silane as a function of temperature and at different total pressures, with and without hydrogen, based on the growth process described by Kossel and Stranskii (Mullin 1972; Strickland-Constable 1968) where adatoms arrive at the surface and diffuse to kink sites where they are incorporated in the crystal lattice (Dhanasekaran and Ramasamy 1981; Hartman 1973). Burton et al (1951) have given the mathematical and physical frame work to calculate the kinetics of crystal growth.

The expressions for the equilibrium concentration of critical nuclei of silicon on $\mathrm{SiO}_{2}$ and $\mathrm{Si}_{3} \mathrm{~N}_{4}$ substrates have been established and taking into account the $\mathrm{O}-\mathrm{H}$, $\mathrm{N}-\mathrm{H}$ and $\mathrm{Si}-\mathrm{H}$ bond energies, the different behaviour of the silicon nucleus on the $\mathrm{SiO}_{2}$ and the $\mathrm{Si}_{3} \mathrm{~N}_{4}$ substrates can be explained qualitatively. It is found experimentally that the behaviour of equilibrium concentrations of the silicon nucleus on the $\mathrm{SiO}_{2}$ substrate increases with temperature in the range $600-900^{\circ} \mathrm{C}$, while beyond $900^{\circ} \mathrm{C}$ it tends to decrease, whereas the concentration of silicon on the $\mathrm{Si}_{3} \mathrm{~N}_{4}$ substrate is found to decrease with increase of temperature. At high temperatures the growth rate of

- To whom all correspondence should be addressed. 
silicon is determined by gas phase diffusion of the reactant to the growing interface and at low temperatures surface reactions determine the growth rate, independent of the magnitude of the total pressure. In the present investigation the growth rate of silicon on silicon from silane, using hydrogen as a carrier gas, is evaluated in the temperature range $600-900^{\circ} \mathrm{C}$ by considering a reaction scheme including the dissociation of $\mathrm{SiH}_{4}$ into $\mathrm{SiH}_{2}$, adsorption of $\mathrm{SiH}_{2}$ on the lattice, surface diffusion of $\mathrm{SiH}_{2}$ to the free step and then to the kink site. It is observed that the growth rate of silicon is proportional to the ratio of the partial pressure of $\mathrm{SiH}_{4}$ to that of $\mathrm{H}_{2}$ in the case of the partial pressure of $\mathrm{H}_{2}$ exceeding $10^{-2}$ bar. If the partial pressure of $\mathrm{H}_{2}$ is low, then the growth rate is independent of the total pressure and the partial pressure of hydrogen.

\section{Nucleation of silicon on $\mathrm{SiO}_{2}$ and $\mathrm{Si}_{3} \mathbf{N}_{4}$ substrates}

According to the classical heterogeneous nucleation theory, the balance of the cohesion between the silicon atoms in the cluster and the adhesion between silicon and foreign substrate determines the shape of the nucleus. For high adhesion energy the nucleus will spread on the foreign substrate, for high cohesive forces the nucleus will have a more or less spherical shape which resembles that for homogeneous nucleation (Bloem and Giling 1978).

The net free energy change upon the formation of a cap-shaped silicon embryo on the substrate, taking into account the net interfacial energy terms and the volume free energy change is (Sigsbee 1969)

$$
\begin{aligned}
\Delta G= & -\frac{4}{3} \pi r^{3}\left(\frac{k T}{v} \ln \frac{p}{p_{0}}\right)\left[\left(2-3 \cos \theta+\cos ^{3} \theta\right) / 4\right]+ \\
& +4 \pi r^{2}[(1-\cos \theta) / 2] \sigma_{g n}+\pi r^{2} \sin ^{2} \theta\left(\sigma_{s n}-\sigma_{s \theta}\right),
\end{aligned}
$$

where $r$ is the radius of the silicon embryo, $k T \ln p / p_{0}$ is the supersaturation function, $\sigma_{g n}, \sigma_{s n}$ and $\sigma_{s g}$ are the interfacial forces between nucleus and gaseous phase, substrate and nucleus, and substrate and gaseous phase, respectively, and $\theta$ is the contact angle. For the critical nucleus, the free energy of formation is

$$
\Delta G^{*}=\frac{16 \pi \sigma_{g n}^{3} v^{2}}{3\left(k T \ln p / p_{0}\right)^{2}} \phi(\theta)
$$

where

$$
\phi(\theta)=\left(2-3 \cos \theta+\cos ^{3} \theta\right) / 4 .
$$

The epitaxial position of the nucleus will have a smaller contact angle $\theta$ on the foreign substrate and consequently a lower value of the energy of formation of the nucleus. This formation energy in turn strongly depends on the supersaturation. This leads to a relation between incoming flux, substrate temperature and nucleation behaviour. The concentration of the critical nuclei having $n^{*}$ silicon atoms formed on the substrate is given by

$$
\frac{C\left(n^{*}\right)}{C_{s}}=\left(\frac{C(1)}{C_{s}}\right)^{n *} \exp \left(-\Delta G^{*} / k T\right),
$$

where $C_{s}$ is the number of sites on the substrate and $C(1)$ is the monomer concentration.

The above classical nucleation theory is used to explain qualitatively the nucleation 


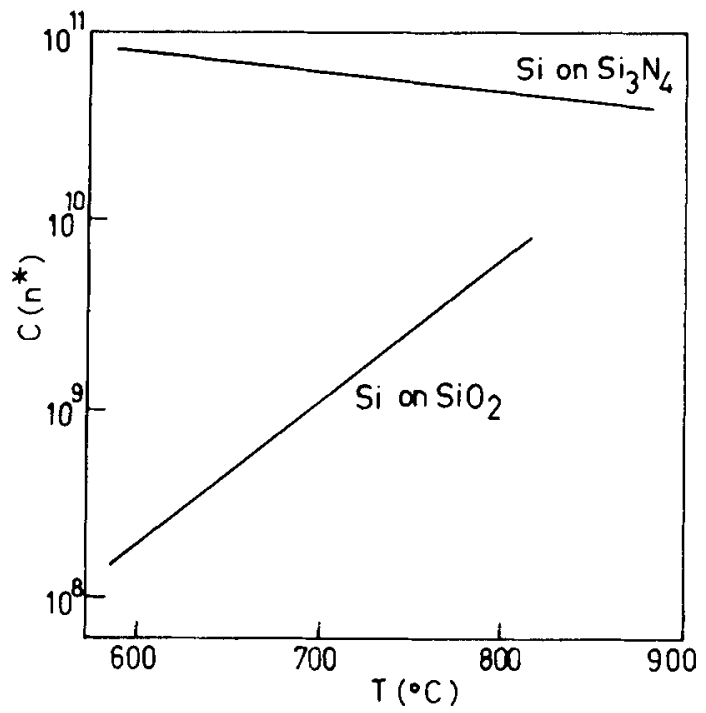

Figure 1. Typical experimental variation of the equilibrium concentration of the silicon nucleus as a function of temperature for silane, using hydrogen as a carrier gas, on $\mathrm{SiO}_{2}$ and $\mathrm{Si}_{3} \mathrm{~N}_{4}$ substrates.

behaviour of silicon on $\mathrm{SiO}_{2}$ and $\mathrm{Si}_{3} \mathrm{~N}_{4}$ substrates. Figure 1 shows the experimental observations of typical variation of silicon cluster concentration with substrate temperature for silane in hydrogen as a carrier gas on $\mathrm{SiO}_{2}$ and $\mathrm{Si}_{3} \mathrm{~N}_{4}$ substrates in the range $600-900^{\circ} \mathrm{C}$ (Claassen and Bloem 1981). It can be observed that the concentration of silicon nuclei on $\mathrm{SiO}_{2}$ substrates increases with increasing temperature whereas the density of silicon clusters on $\mathrm{Si}_{3} \mathrm{~N}_{4}$ substrates decreases in the temperature range of $600-900^{\circ} \mathrm{C}$ using hydrogen as the carrier gas. The difference in nucleation behaviour of silicon between $\mathrm{SiO}_{2}$ and $\mathrm{Si}_{3} \mathrm{~N}_{4}$ substrates is explained by a strong adsorption of atomic hydrogen on the $\mathrm{SiO}_{2}$ substrate. Since the difference between the $\mathrm{O}-\mathrm{H}$ (102 kcal/mole) and the $\mathrm{N}-\mathrm{H}$ bond energies $(83 \mathrm{kcal} / \mathrm{mole})$ is about $20 \mathrm{kcal} / \mathrm{mole}$ (JANAF Tables 1971), the energy of formation of the silicon nucleus on the $\mathrm{SiO}_{2}$ substrate is very different from that of the silicon cluster on $\mathrm{Si}_{3} \mathrm{~N}_{4}$ substrate. More theoretical work is required to compare the observed experimental results quantitatively.

\section{Growth of silicon layers from silane}

In the temperature range of $600-900^{\circ} \mathrm{C}$, the growth of silicon is limited by a chemical or surface controlled process. It is assumed for the low temperature growth of silicon that adatoms arriving at the step, diffuse to kinks which are present on the step with a velocity sufficiently high to assure an uninterrupted lateral movement of the steps (Bloem and Giling 1978). If the chemical reaction is rapid then a general model remains in which silicon adatoms diffuse over the surface to steps and along the step to a stable kink position (Dhanasekaran 1984). Reactions such as adsorption, desorption, surface diffusion to the step and then one-dimensional diffusion to the kink involve activation 
energy. The growth rate $R$ resulting from these processes can be described by the expression

$$
R \propto \exp \left(-\Delta H / R_{A} T\right),
$$

where $\Delta H$ is the apparent activation energy for the processes, $R_{A}$ is the gas constant and $T$ is the absolute temperature. According to our scheme of reaction, the total activation energy can be assumed to be made up of five parts, i.e.,

$$
\Delta H=\Delta H_{1}+\Delta H_{2}+\Delta H_{3}+\Delta H_{4}+\Delta H_{5},
$$

where $\Delta H_{1}, \Delta H_{2}, \Delta H_{3}, \Delta H_{4}$ and $\Delta H_{5}$ are the activation energies associated with the dissociation of $\mathrm{SiH}_{4}$ in the gaseous phase, adsorption, surface diffusion to the free step, diffusion to the kink site and growth of silicon layers respectively. The total activation energy for the growth of silicon from silane in hydrogen as carrier gas is about $40 \mathrm{kcal} / \mathrm{mole}$ (Claassen and Bloem 1981).

A reaction scheme will be presented in the following including the dissociation of $\mathrm{SiH}_{4}$ to $\mathrm{SiH}_{2}$, adsorption of $\mathrm{SiH}_{2}$ on the lattice, surface diffusion of $\mathrm{SiH}_{2}$ to the free step and then to kink site to explain the experimental observations. The following sequence of steps are taken into account:

(i) The dissociation reaction in the gaseous phase

$$
\mathrm{SiH}_{4} \underset{k_{-1}}{\stackrel{k_{1}}{\rightleftharpoons}} \mathrm{SiH}_{2}+\mathrm{H}_{2} \text {. }
$$

The heat of reaction $\left(\Delta H_{1}\right)$ for the above reaction is $52 \mathrm{kcal} / \mathrm{mole}$ (Newman et al 1979). (ii) Adsorption of $\mathrm{SiH}_{2}$ on a free surface site

$$
\mathrm{SiH}_{2}+\underset{k_{-2}}{\stackrel{k_{2}}{\rightleftharpoons}} \mathrm{SiH}_{2}^{*}
$$

where ${ }^{*}$ denotes a free site on the surface. The heat of adsorption of $\mathrm{SiH}_{2}$ on the silicon surface is approximately $-73 \mathrm{kcal} / \mathrm{mole}$ (Chernov 1977). From (7) and (8), the concentration of $\mathrm{SiH}_{2}$ is

$$
\left[\mathrm{SiH}_{2}\right]=p_{\mathrm{SiH}_{4}} k_{1} /\left\{k_{-1} p_{\mathrm{H}_{2}}+k_{2}[*]\right\} \text {. }
$$

(iii) Surface diffusion of $\mathrm{SiH}_{2}$ to a free step site * (step)

$$
\mathrm{SiH}_{2}^{*}+*(\text { step }) \underset{k_{-3}}{\stackrel{k_{3}}{\rightleftharpoons}} \mathrm{SiH}_{2}^{* *} \text {. }
$$

Heat of above reaction is about $-73 \mathrm{kcal} /$ mole. The concentration of $\mathrm{SiH}_{2}^{*}$ is

$$
\left[\mathrm{SiH}_{2}^{*}\right]=\left[\mathrm{SiH}_{2}\right][*] k_{2} /\left\{k_{-2}+k_{3}[*(\text { step })]\right\} \text {. }
$$

(iv) Diffusion to the free kink site * (kink)

$$
\begin{aligned}
& \mathrm{SiH}_{2}^{* *}+*(\text { kink }) \underset{k_{-4}}{\stackrel{k_{4}}{\rightleftharpoons}} \mathrm{SiH}_{2}^{* * *}, \\
& {\left[\mathrm{SiH}_{2}{ }^{* *}\right]=\left[\mathrm{SiH}_{2}{ }^{*}\right][*(\text { step })] k_{3} /\left\{k_{-3}+k_{4}[*(\text { kink })]\right\} .}
\end{aligned}
$$

(v) Growth of silicon and release of hydrogen

$$
\begin{aligned}
& \mathrm{SiH}_{2} * * * \underset{h_{-5}}{\stackrel{k_{3}}{\rightleftharpoons}} \mathrm{Si}(\text { crystal })+\mathrm{H}_{2}+{ }^{*}+{ }^{*}(\text { step })+{ }^{*}(\text { kink }), \\
& {\left[\mathrm{SiH}_{2}^{* * *}\right]=\left[\mathrm{SiH}_{2}^{* *}\right][*(\text { kink })] k_{4} /\left\{k_{-4}+k_{5}\right\} .}
\end{aligned}
$$


The $\left[\mathrm{SiH}_{2}{ }^{* * *}\right]$ can be calculated by assuming the steady state conditions. Using the assumptions that $k_{4} \ll k_{-3} \ll k_{2}, k_{3}\left[*(\right.$ step) $] \ll k_{-2} \ll k_{1}$ and $k_{5} \ll k_{-4}$ and from (9), (11), (13) and (15), one can get

$$
\left[\mathrm{SiH}_{2}^{* * *}\right]=\frac{k_{1} k_{2} k_{3} k_{4} p_{\mathrm{SiH}_{4}}[*]\left[{ }^{*}(\text { step })\right]\left[{ }^{*}(\text { kink })\right]}{\left(k_{-1} p_{\mathrm{H}_{2}}+k_{2}\left[{ }^{*}\right]\right) k_{-2} k_{-3} k_{-4}} .
$$

With $k_{i} / k_{-i}=C_{i} \exp \left(-\Delta H_{i} / R_{A} T\right)$ (Claassen and Bloem 1985), (16) can now be rearranged as

$$
\begin{aligned}
{\left[\mathrm{SiH}_{2}^{* * *}\right]=} & C_{1} C_{2} C_{3} C_{4} \frac{p_{\mathrm{SiH}_{4}}[*][*(\text { step })][*(\text { kink })]}{p_{\mathrm{H}_{2}}+\left(k_{2}[*] / k_{1}\right)} \\
& \times \exp \left\{-\left(\Delta H_{1}+\Delta H_{2}+\Delta H_{3}+\Delta H_{4}\right) / R_{A} T\right\} .
\end{aligned}
$$

The growth rate of silicon is given by

$$
R=C_{5}\left[\mathrm{SiH}_{2}^{* * *}\right] \exp \left(-\Delta H_{5} / R_{A} T\right)
$$

Incorporating the value of $\left[\mathrm{SiH}_{2}{ }^{* *}\right]$ from (17) in (18), the growth rate becomes

$$
R=\sum_{i=1}^{5} C_{i} \frac{p_{\mathrm{SiH}_{4}}\left[^{*}\right]\left[{ }^{*}(\text { step })\right]\left[{ }^{*}(\mathrm{kink})\right]}{p_{\mathrm{H}_{2}}+\left(k_{2}[*] / k_{-1}\right)} \exp \left(-\sum_{i=1}^{5} \Delta H_{i} / R_{A} T\right)
$$

It is observed in (19) derived above that the growth rate of silicon from silane is proportional to $p_{\mathrm{SiH}_{4}} / p_{\mathrm{H}_{2}}$ when hydrogen is present in the carrier gas and $k_{2} / k_{-1}<p_{\mathrm{H}_{2}}$. In the temperature region of $600-900^{\circ} \mathrm{C}$, the partial pressure of hydrogen is found to have a pronounced influence. Figure 2 shows the typical experimental variation of the

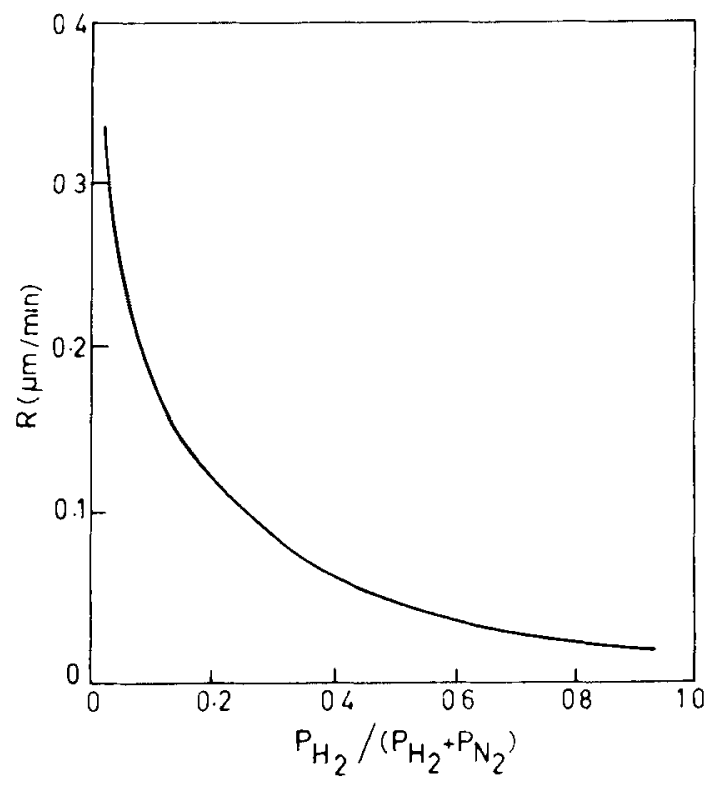

Figure 2. Experimental variation of the growth rate of silicon at $700^{\circ} \mathrm{C}$, for $0-2$ volume percent silane and different mixtures hydrogen and nitrogen at atmospheric pressure (Claassen and Bloem 1981). 
growth rate of silicon at $700^{\circ} \mathrm{C}$ for an input concentration of 0.2 volume percent silane and different mixtures of hydrogen and nitrogen (Claassen and Bloem 1981). A high growth rate of silicon in inert ambients is observed, much higher than in hydrogen. Therefore, if the partial pressure of hydrogen is zero or very less, the growth rate in inert gas is much larger than in hydrogen. As discussed above, in the temperature range of $600-900^{\circ} \mathrm{C}$, the growth of the silicon layers is the surface controlled reaction and the apparent activation energy $(\simeq 40 \mathrm{kcal} / \mathrm{mole})$ is almost independent of the partial pressure of hydrogen. In the present model, the best fit of the experimental data can be expected in the low temperature region with small temperature dependence of $k_{2} / k_{-1}$ combined with a concentration of free surface sites and free step sites almost equal to the total number of sites. Based on the reaction scheme given above, an evaluation of $\Delta H_{4}$ and $\Delta H_{5}$ can be made, giving $\Delta H_{4}+\Delta H_{5} \simeq 130 \mathrm{kcal} / \mathrm{mole}$.

\section{Conclusion}

The nucleation of silicon on $\mathrm{SiO}_{2}$ and $\mathrm{Si}_{3} \mathrm{~N}_{4}$ substrates has been qualitatively studied using the classical heterogeneous nucleation theory. The experimental observations of silicon nuclei on $\mathrm{SiO}_{2}$ substrates which increase with increasing temperature while decreasing on $\mathrm{Si}_{3} \mathrm{~N}_{4}$ substrates, using hydrogen as a carrier gas is explained on the basis of the relative bond strengths of the $\mathrm{O}-\mathrm{H}(102 \mathrm{kcal} / \mathrm{mole}), \mathrm{N}-\mathrm{H}(83 \mathrm{kcal} / \mathrm{mole})$ and Si-H bonds $(70 \mathrm{kcal} / \mathrm{mole})$.

In the temperature region, $600-900^{\circ} \mathrm{C}$, the surface reactions determine the growth rate of silicon, which decreases with increasing hydrogen partial pressure giving

$$
R \propto p_{\mathrm{SiH}_{4}} /\left(\frac{k_{2}[*]}{k_{1}}+p_{\mathrm{H}_{2}}\right) .
$$

For values of the partial pressure of hydrogen exceeding $10^{-2}$ bar, the growth rate of silicon is directly proportional to $p_{\mathrm{SiH}_{4}} / p_{\mathrm{H}_{2}}$.

\section{Acknowledgement}

One of the authors (RD) thanks the UGC, New Delhi for financial support.

\section{References}

Aoyama T, Inoue Y and Suzuki T 1981 Semiconductor silicon 1981 (eds.) H R Huff, R J Kriegler and Y Takeishi (Pennington: The Electrochemical Society)

Bloem J 1970 J. Electrochem. Soc. 1171397

Bloem J and Giling L J 1978 Current topics in material science (ed.) E Kaldis (Amsterdam: North-Holland) vol. 1

Burton W K, Cabrera N and Frank F C 1951 Philos. Trans. R. Soc. 243299

Bylander E G 1962 J. Electrochem. Soc. 1091171

Chernov A A 1977 J. Cryst. Growth 4255

Claassen W A P and Bloem J 1981 Semiconductor silicon 1981 (eds) H R Huff, R J Kriegler and Y Takeishi (Pennington: The Electrochemical Society).

Claassen W A P and Bloem J 1985 to be published

Dhanasekaran R and Ramasamy P 1981 Cryst. Res. Technol. 161347

Dhanasekaran R and Ramasamy P 1982 J. Phys. D: Appl. Phys. 151407 
Dhanasekaran R 1984 Some studies on surface nucleation, crystal-solution interface and precipitation of oxides in $\mathrm{CZ}$ silicon Ph.D. thesis, Anna University, Madras

Hartman P (ed.) 1973 Crystal growth: an introduction (Amsterdam: North Holland)

JANAF Thermochemical Tables 1971 2nd ed., NSRDS-NBS-37

Mullin J W 1972 Crystallisation (London: Butterworths)

Newman L J, O'Neal H E, Ring M A, Fleska F and Shipley N 1979 Int. J. Chem. Kinetics 111167

Sigsbee R A 1969 Nucleation (ed.) A C Zettlemoyer (New York: Marcel Dekker)

Sladek K J 1971 J. Electrochem. Soc. 118654

Strickland-Constable R F 1968 Kinetics and mechanism of crystallisation (London: Academic Press) 